\title{
Laboratory evaluation of Novalurone as an Insect Growth Regulator (IGR) against the immature DDT resistant Phlebotomus argentipes (Diptera: psychodidae)
}

\author{
Aarti Rama ${ }^{1,2,3}$ and Vijay Kumar ${ }^{*}$
}

*Correspondence: vijayrnagar@hotmail.com

CrossMark

\& Click for updates

\begin{abstract}
'Department of Vector Biology and Control, ICMR- Rajendra Memorial Research Institute of Medical Sciences, Agamkuan, Patna 800007 , Bihar, India.

${ }^{2}$ Department of Zoology (University of Calcutta), 35, B.C. Road, Kolkata-700 019, India.

${ }^{3}$ Bihar Technical Support Program (BTSP), CARE India, Mirchaibari, Katihar - 854 105, Bihar, India.
\end{abstract}

\begin{abstract}
Female sand flies Phlebotomus argentipes are well-established pathogen transmitter for Visceral Leishmaniasis (VL) among humans and Dichlorodiphenyltrichloroethane (DDT) served as an important tool for controlling their population. After the decades of DDT use, P. argentipes has developed resistance against it affecting every aspect of vector control at grass-root level. In a way of exploring new 'strategic weapon' against sand flies, Novalurone - a noble Insect Growth Regulators (IGRs), inhibiting life-cycle and checking insect population at their non-infective stage has been evaluated for the first time ever against the laboratory colonized DDT resistant sand flies. It was observed that DDT resistant sand flies tolerating insecticide pressure successfully exhibited susceptibility at highest concentration of Novalurone processed larval diet (i.e., at $150000 \mathrm{ppm}$ ) following slowed growth rate that doesn't allowed them to metamorphed into the pupal stage. Moreover, their survival $(1.8 \pm 94.50)$ was observed to be lasted till $2^{\text {nd }}$ stage only in which they attained absolute mortality. These preliminary laboratory based results certifies Novalurone to be very much effective for nailing effective checks upon natural growth process of immature DDT resistant sand flies and hence could be incorporated as an important preposition as alone or as a synergist with insecticide for total and long-lasting control over the VL vector population.
\end{abstract}

Keywords: Phlebotomus argentipes, Visceral Leishmaniasis (VL), Dichlorodiphenyltrichloroethane (DDT), sand flies, Novalurone, Insect Growth Regulator (IGR)

\section{Introduction}

Female Phlebotomus argentipes (Diptera: Psychodidae) are an obligatory blood-feeders $[\mathbf{1 , 2}]$ and as a consequences of their blood-feeding lifestyle, they become pertinent to harbor Leishmania donovani (Kinetoplastida:Trypanosomatidae) and deliver the lethal-most disease Visceral Leishmaniasis ( $\mathrm{VL}$ ) in Indian subcontinent [3,4]. For controlling the disease expansion, vector control strategies remains mainstay.

At VL endemic Indian states, Indoor Residual Spray (IRS) with the insecticide of choice i.e., Dichlorodiphenyltrichloroethane (DDT) remained very popular as a vector control tool since 1953 $[5,6]$ as VL vector population were highly susceptible to it. But, after the decades of extensive application of DDT, P. argentipes has developed the capacity to tolerate its toxicity to such an extent that instead of getting killed, it attained tolerance/ resistance against it [7-16]. Increased number of vector survival under the insecticidal effect authenticates the insecticide resistance ultimately affecting every aspect of vector control at grass-root level.

In this regards, various synthetic insecticides, Insect Growth Regulators (IGRs) being specific in their mode of action over the insect pests as well as safer to the non-target organisms along with environment [17] sought its potentiality for providing maximum control without disturbing ecological harmony. IGRs either specifically interrupts the functioning of endocrine mechanism or synthesis of chitin in cuticular structures during 
development of insect $[17,18]$. In addition with emergence inhibition, these IGRs potentially affect the fecundity and survival of mosquitoes at sublethal concentrations $[19,20]$. The efficacy of various synthetic IGRs such as diflubenzuron, methoprene, pyriproxyfen, ivermectine, novaluron, has been well-established against mosquitoes $[\mathbf{2 1 , 2 2 ]}$ and even against phlebotomine sand flies of other species $[\mathbf{2 3}, \mathbf{2 4}]$ but it has never been explored in case of Indian VL vector. Therefore, this study has been designed and performed to promulgate the efficacy of Novaluron as an IGR for checking the population of DDT resistant $P$. argentipes at their non-infective stages.

\section{Materials and Methods}

For evaluating the efficacy of novalurone against the developing stages of DDT resistant $P$. argentipes, DDT resistant strained sand flies served as the 'backbone element' for this study. This colony was established during 2014-15 following the protocol detailed in our previous report $[15,25]$ and well maintained up till $17^{\text {th }}$ generation. The experiments were carried out with sand flies of DDT resistant colony (at their $16^{\text {th }}$ and $17^{\text {th }}$ generation) during the months of SeptemberDecember 2017. Also the sterilized sand flies that had never been exposed to any insecticide, being procured from the non-resistant colony, served as the control sample for our experiments. These sand flies were maintained at the controlled environment i.e., $28 \pm 2^{\circ} \mathrm{C} ; 80 \pm 5 \% \mathrm{RH}$ and 12:12 (L: D) hrs of photoperiod of insectariums at the Department of Vector Biology and Control of Rajendra Memorial Research Institute of Medical Sciences (Indian Council of Medical Research), Agamkuan, Patna-07, Bihar, India.

Another key component for this study was the Novaluron PESTANAL ${ }^{\circ}$ (C17H9CIF8N2O4), (Product No. 32419, Batch no. BCBS5934V, analytical grade, manufacturing date- $25^{\text {th }}$ August 2016) manufactured by India based company Sigma-Aldrich ${ }^{\mathrm{TM}}$, that was selected as an Insect Growth Regulators (IGRs) for its evaluation against the growth and development of noninfective stages of DDT resistant sand flies.

Under the methodology, healthy male rabbits, Oryctolagus cuniculus (Legomorpha: leporidae) were procured from the Animal House division of Rajendra Memorial Research Institute of Medical Sciences (ICMR), Agamkuan, Patna (Bihar). After providing blood meal to the newly emerged sand flies, the rabbits were returned back to the animal house, where they were separately kept in animal cages ( $12 \mathrm{sq} \mathrm{ft}$ with grids of 2.5 inches) and supplemented with food and water according to the diet chart of animal house of research institute. For present study "Principles of laboratory animal care" (NIH publication No. 85-23, revised 1985) were followed for conducting research experiments involving animal.

Out of the two healthy and mature male rabbits, first one was randomly assigned for the diet to be supplemented with Novaluron at the dose of $5 \mathrm{gm} /$ day continuously for five days $[26,27]$ while other one was fed with normal Novaluron-freed diet. Prior experimentation, the body weight of these rabbits was recorded the day before diet treatments.

\section{Larval food preparation for developing stages}

The larval food preparation for this experiment was done in accordance with protocols detailed in our previous report [28]. In brief, following to the diet supplementation, next day all the fecal pellets expelled out by both experimental as well as control rabbits were collected separately in labeled and uncovered plastic trays and were allowed to dry at room temperature, varied between $28-30^{\circ} \mathrm{C}$, away from the approach of sunlight. After complete desiccation, and manual removal of foreign particles viz., mites and fungus, these were then offered to the mixer grinder (Philips ${ }^{\oplus}$ HL1618, product code 117137, Manufacturing certificate no. HP/14/002/2003), purposely for fine grinding. The ground feces were sieved and kept properly as a 'rabbit feces powder' in air-tight containers and well demarcated as 'experiment' and 'control'.

3 doses of experimental larval food were prepared by mixing Novaluron at $5 \mathrm{gm}, 10 \mathrm{gm}$ and $15 \mathrm{gm}$ per $100 \mathrm{gm}$ of rabbit feces powder to give 'Novalurone treated larval food' at the concentration of 50000, 100000 and 150000 ppm respectively, whereas control larval food (i.e., Novalurone freed larval food) were kept away either from IGR or any other chemicals especially from insecticides as illustrated in Figure 1. These larval foods were prepared for the next bioassay stage of this experiment.

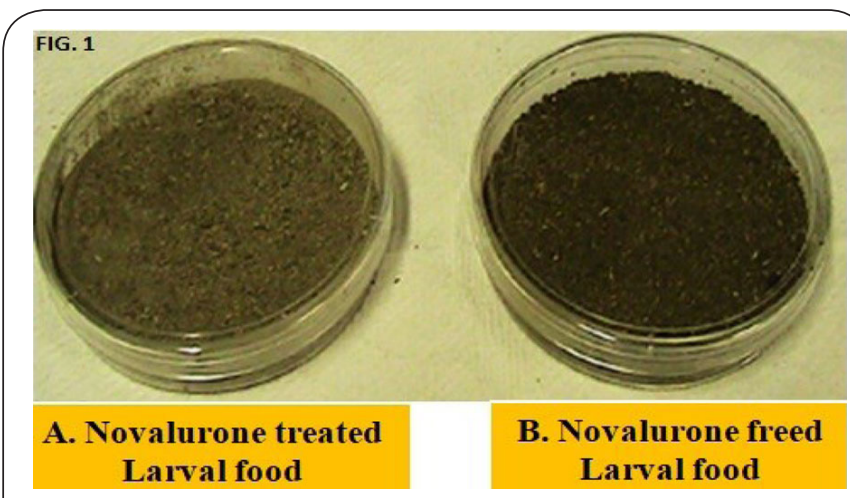

Figure 1. Experimented larval food A. Novalurone treated and B. Novalurone freed prepared for feeding immature stages of sand flies.

\section{Bioassay}

Following blood-meal supplementation to the newly emerged out female sand flies of DDT resistant colony as well as nonresistant colony in accordance with established procedure as dealt in our previous report $[15,25,28]$, were then gently aspirated into the freshly prepared plaster-surfaced oviposition pots $(7 \mathrm{~cm}$ height $\times 7 \mathrm{~cm}$ diameter), finely lined with filter paper strips [29].

10 fully engorged sand flies along with equal no. of male sand flies were confined in 3 separated "experimental oviposition pots" allotted for feeding and observing the growth 
and development of emergents under the effect of IGR i.e., Novalurone treated larval food at the concentration of 50000 , 100000 and 150000 ppm respectively. Also, 10 male and 10 blood-fed female sand flies were separately confined in the oviposition pots labeled as "control oviposition pots" purposely for observing and comparing the growth of immature stages under the effect of normal, untreated larval food.

After confinement of insects, these oviposition pots were held carefully under the controlled environment of laboratory of Vector Biology and Control department of RMRIMS (ICMR), Patna, and were regularly monitored for egg deposition by the female insect cohort, following of which, the hatchlets emerged out from them were vigilantly observed for ascertaining their survivorship and fine health [28]. Soon, after the egg's hatching, the observed neonates of each experimental along with controlled group were supplemented with Novalurone treated larval food and novalurone-freed larval food respectively. After food supplementation phase, the oviposition pots were kept carefully and were observed daily till their transformation into adult flies and larval food supplementation to the immature larval stages were repeated again only at the condition of food scarcity. Here, larvae were considered as death exhibiting size and color differentiation, failing to produce any active movement and any favorable response against soft stimuli offered to them with blunt needle as illustrated in Figure 2.

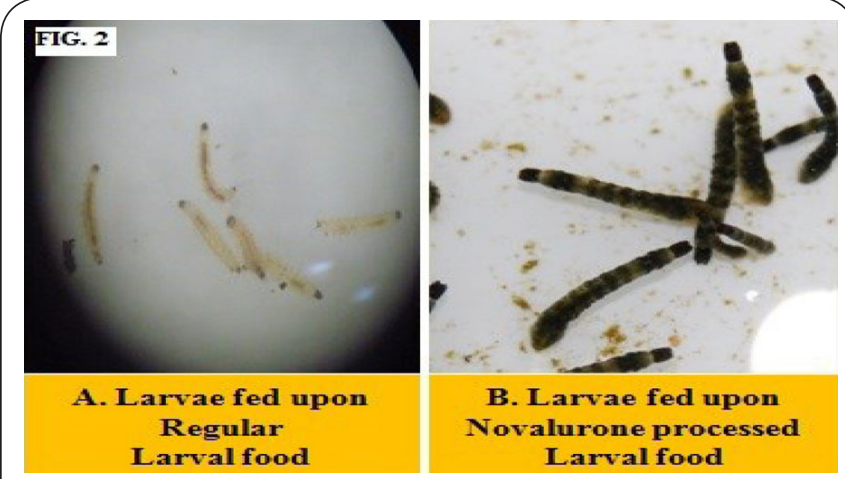

Figure 2. Comparision based effect of Novalurone over the survival and growth of DDT resistant $P$. argentipes larvae when fed upon A. Novalurone freed regular larval diet as compared with B. Novalurone treated larval food.

All the microscopic observations, positive growth comparisons and confirmations of health and nourishment of active immature stages were carried out by the sand flies' expert with the help of stereoscopic microscope (Carl Zeiss Stereoscopy Microscope, Austria; Model 426126), and hence the obtained data were tabulated in terms of mean and percentage of larvae survived and transformed into its next developing stage in each experimental sets and comparing the same with control ones with a repeated measures ANOVA performed with the GLM procedure and were tabulated detailing each in result section.

\section{Results}

Overall, 80 male and 80 female sand flies (20 male and 20 female sand flies for each 3 experimental doses as well as for control) in 2 experimental replicates were used for examining the efficacy of Novaluron against the growth and development of emergent at their non-infective stage only. In aggregate, 60 engorged female sand flies (of 3 experimental doses of IGR treated larval food at the concentration of 50000, 100000 and 150000 ppm) deposited 111, 93, 152 eggs in experimental oviposition pots respectively whereas 20 female sand flies of control sets laid 107 eggs. With 92, 83, 129 and 95 recorded hatchings, these were always observed to be more than $80 \%$ i.e., $82.88 \%, 89.24 \%, 84.86 \%$ and $88.78 \%$ for each 3 experimental and control oviposition pots respectively.

Following the survivorship trends of larvae under the influence of IGR treated larval food at different concentration, it was observed that Novalurone at the concentration of $50000 \mathrm{ppm}$ causes survivorship of larvae from their $1^{\text {st }}$ stage $(7.5 \pm 76.78)$ to their $4^{\text {th }}$ stage $(1.57 \pm 24.60)$, while gradual increased concentration of Novalurone at 100000 ppm affected the survivorship of larvae up till $3^{\text {rd }}$ stage $(1.38 \pm 63.80)$. Much adversely, larvae survivorship had been observed to be decreased significantly in presence of highest concentration of Novalurone i.e., at 150000 ppm, exhibiting survivorship $(1.8 \pm 94.50)$ to be restricted till $2^{\text {nd }}$ staged only as compared with other two experimented concentration of larval diet (i.e., $50000 \mathrm{ppm}$ or $100000 \mathrm{ppm}$, with larval survivorship $1.57 \pm 24.60$ at $4^{\text {th }}$ stage and $1.38 \pm 63.80$ at $3^{\text {rd }}$ stage respectively). On contrary to this, larvae of controlled oviposition pots, exhibited normal growth and successful transformation as adult flies $(0.32 \pm 58)$ after crossing its next intermediate stages viz., pupal stage (1.6 \pm 87.54$)$ as detailed in Table 1. The values of skewness and kurtosis for control as well as for experimental replica were greater than \pm 1 .

\section{Discussion}

DDT has been used as a key insecticide against the Indian VL vector specie, P. argentipes [5,30]. Continuous and uneven application of this insecticide for several years led to the development of tolerance/resistance among these 'minute terrorist' against this insecticide [7-14,16,25,31]. Although, the continuous perusal of DDT had evoked the instances of insecticide resistant against it among sand flies, but along with that it also opportunise new strategies viz., introduction of IGR for sustainable eye-check over the vector abundance as well as pathogen transmission by them.

IGR is the chemical substances that emasculate growth processes of insects having rapid developmental cycle and passes through more than one generation per season ultimately probing check upon their population growth [32]. It can be exploited either by providing direct exposure of insect to IGRs and observing their functions or by assessing the insects' development influenced by hormones that will interfere with normal insect growth and development $[23,24]$. 
Rama et al. Trends in Vector Research and Parasitology 2021,

Table 1. Bioassay test results detailing the sand flies' and their emergent probed for examining the efficacy of Novalurone treated larval food against the growth and development of immature stages of DDT resistant $P$. argentipes and comparing the same with controlled sand flies (i.e., non-resistant sand flies) supplemented with untreated larval food (i.e., Novalurone freed larval food).

\begin{tabular}{|c|c|c|c|c|}
\hline \multicolumn{5}{|c|}{ DETAILS OF SAND FLIES' AND ITS EMERGENTS PRIOR EXPERMENTATION } \\
\hline $\begin{array}{l}\text { No. of Sand flies used } \\
\text { for experiment }\end{array}$ & $\begin{array}{l}20 \text { male and } \\
20 \text { females and flies }\end{array}$ & $\begin{array}{l}20 \text { male and } 20 \\
\text { females and flies }\end{array}$ & $\begin{array}{l}20 \text { male and } 20 \\
\text { females and flies }\end{array}$ & $\begin{array}{l}20 \text { male and } 20 \\
\text { females and flies }\end{array}$ \\
\hline $\begin{array}{l}\text { Eggs oviposited by } \\
\text { female sand flies }\end{array}$ & 111 & 93 & 152 & 107 \\
\hline $\begin{array}{l}\text { Hatchings } \\
\text { (Number } \pm \text { Percentage) }\end{array}$ & $92 \pm 82.88$ & $83 \pm 89.24$ & $129 \pm 84.86$ & $95 \pm 88.78$ \\
\hline \multicolumn{5}{|c|}{$\begin{array}{l}\text { SURVIVORSHIP OF DEVELOPING STAGES POST TREATMENT WITH IGR } \\
\text { (Mean } \pm \text { Percentage) }\end{array}$} \\
\hline & $50000 \mathrm{ppm}$ & $100000 \mathrm{ppm}$ & $150000 \mathrm{ppm}$ & Untreated (Control) \\
\hline $1^{\text {st }}$ stage larvae & $(7.5 \pm 76.78)$ & $(2.5 \pm 88.39)$ & $(1.9 \pm 87.33)$ & $(13.6 \pm 25.47)$ \\
\hline $2^{\text {nd }}$ stage larvae & $(6.4 \pm 85.04)$ & $(2.1 \pm 85.32)$ & $(1.8 \pm 94.50)$ & $(9.8 \pm 72.05)$ \\
\hline $3^{\text {rd }}$ stage larvae & $(4.82 \pm 75.39)$ & $(1.38 \pm 63.80)$ & --- & $(7.5 \pm 79.71)$ \\
\hline $4^{\text {th }}$ stage larvae & $(1.57 \pm 24.60)$ & ---- & ---- & $(2.52 \pm 34.05)$ \\
\hline Pupae & ---- & ----- & ---- & $(1.6 \pm 87.54)$ \\
\hline Adult Emergence & ---- & ----- & --- & $(0.32 \pm 58)$ \\
\hline
\end{tabular}

Besides being so impactful, having greater specificity and least hazardous from the environmental perspective, it failed to gain attention for controlling sand fly population at their developing stage.

Therefore, in continuation with our previous reports dealing insecticide resistance implicating fitness and reproductive cost among the homozygous DDT resistant strained $P$. argentipes [33] following its colonization in controlled condition [15], present study has been designed to explore the efficacy of IGR against the population of DDT resistant sand flies at their 'dormant' stages.

For this study, Novalurone mixed food supplementation to the experimental rabbits had been performed in accordance with the previous reports dealing with feed-through insecticide experiments on mosquitoes as well as sand flies of other species $[\mathbf{2 2}, \mathbf{2 3}, \mathbf{2 4}]$ while Novalurone processed fecal matter voided-off by these experimental animals, ensured the two-way participation of IGR to be tested against the larvae and pupae of DDT resistant $P$. argentipes.

The quality of food supplement provided to the experimented rabbit in this study, was observed to be remained unaffected by the incorporation of novaluron and didn't caused any health implications among them when compared with controlled one, confirming novaluron-treated diets to be palatable for them along with other rodents [26]. Therefore, novaluron could be incorporated for baiting other rodents.

Adult female sand flies are responsible agent for pathogenicity transmission among human and hence, adults are more pathogenic than the larval stage [34]. The bioassay experiment results demonstrating susceptibility development towards Novalurone among the experimented DDT resistant sand flies, nullifying resistance factor at their larval stage, establishes its success for checking their population outgrowth at their juvenile stage before reaching to their adult stage.

The larval stage of sand flies are the voracious feeding stage [15] in which insect accomplishes themselves with 'heavy stock' of nutrients that could further be exploited for their next developing stage i.e., pupal stage and help them to emerge out as matured fly [35]. Study result demonstrating at highest concentration of Novalurone processed larval diet

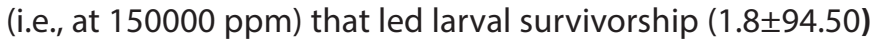
to be restricted at $2^{\text {nd }}$ staged only. At this concentration of Novalurone treated larval diet, larval mortality was recorded to be highest and very speedy as compared to either other two experimented concentration of novalurone treated larval food or untreated normal larval food. Hence, Novalurone treated larval food restrict the larval growth and doesn't allow it to enter into its next developing stage i.e., Pupal stage.

\section{Conclusion}

Therefore, our preliminary lab-based evidence conclude that with increased accumulation of IGR within larval body via Novalurone processed food provide satisfactory checks upon the population outgrowth of insecticide resistant $P$. argentipes at their larval stage and hence doesn't allow them to mature as pathogenic adult sand fly.

It could serve as an important preposition as alone or as a synergist with insecticide for controlling sand fly population at their non-infective stage. Novalurone as an IGR has been successfully used for targeting mosquitoes as well as P. papatasi but against the KA vector, this preliminary lab-based result has to be explored at the field level for including it in 
Rama et al. Trends in Vector Research and Parasitology 2021,

the National Programme for VL elimination.

\section{Competing interests}

The authors declare that they have no competing interests.

\section{Authors' contributions}

\begin{tabular}{|l|c|c|}
\hline Authors' contributions & AR & VK \\
\hline Research concept and design & $\sqrt{ }$ & $\sqrt{ }$ \\
\hline Collection and/or assembly of data & $\sqrt{ }$ & -- \\
\hline Data analysis and interpretation & $\sqrt{ }$ & $\sqrt{ }$ \\
\hline Writing the article & $\sqrt{ }$ & -- \\
\hline Critical revision of the article & -- & $\sqrt{ }$ \\
\hline Final approval of article & -- & $\sqrt{ }$ \\
\hline Statistical analysis & $\sqrt{ }$ & -- \\
\hline
\end{tabular}

\section{Acknowledgements and fundings}

The authors cordially express their gratitude towards Dr. V. P. Singh, Mr. N. K. Sinha, Mr. S.A. Khan, and all the members of Vector Biology and Control Division of RMRIMS (ICMR) for their excellent technical support and their substantive help during experiment and manuscript documentation session. Thanks are also due to the Scientific Advisory Committee (SAC) of RMRIMS (ICMR), Institutional Ethical Committee as well as to the Animal Ethics Committee for their kind approval to conduct the needful research study. Last but not least, we are also thankful to the research publication committee of ICMRRMRIMS for considering the reports worth publication. This research work has been carried out as an intramural study entitling "Understanding behavioral profile of DDT resistant sand flies for exploring scope of IGR as an alternate technique for containing the population of Phlebotomus argentipes [Study Id. No. INT-119-VBC-2015]" of Rajendra Memorial Research Institute of Medical Sciences (ICMR), Agamkuan, Patna-07, Bihar, and served as the portion of PhD programme entitling "Study of behavioral responses in the offspring emerged out from single parent insect of $4 \%$ DDT resistant strain Phlebotomus argentipes (Diptera: Psychodidae) the vector of kala-azar (Visceral Leishmaniasis) in Indian subcontinent [Registration No. 3700/ PhD. (Sc.) proceed 2014]" progressing at the University of Calcutta, Kolkata (West Bengal), India and financially sponsored by University Grant Commission, India with vide grant number [RGNF 2012-13-ST-BIH-20305] during session 2012-17.

\section{Publication history}

Editor: Werner Apt Baruch, University of Chile, Holland.

Received: 16-June-2021 Final Revised: 29-July-2021

Accepted: 18-Aug-2021 Published: 10-Sep-2021

\section{References}

1. Kumar, V., Kesari, S., Kumari, K., Krishnakumari, B., Venugopalan, R. and Das, P., 2011. Comparison of in vivo host animals as blood-feeding source for laboratory rearing of the sand fly vector Phlebotomus argentipes (Diptera: Psychodidae). Ann. Entomol. Soc. Am. 104(3): 429433.

2. Kumar, V., Krishnakumari, B., Kesari, S., Kumari, K., Kumar, R., Ranjan, A. and Das, P., 2012. Preliminary observations on the female behavior of the Indian sand fly vector, Phlebotomus argentipes (Diptera: Psychodidae). - Ann. Entomol. Soc. Am. 105(2): 201-205.

3. Swaminath, C.S., Shortt, H.E. and Anderson, L.A.P., 2006. Transmission of Indian kala-azar to man by the bites of Phlebotomus argentipes, Ann. and Brun. - Indian. J. Med. Res. 123(3): C473.
4. Sharma, U. and Singh, S., 2008. Insect vectors of Leishmania: distribution, physiology and their control. - J. Vector. Borne. Dis. 45(4): 255-272.

5. Kishore, K., Kumar, V., Kesari, S., Dinesh, D.S., Kumar, A.J., Das, P. and Bhattacharya, S.K., 2006. Vector control in leishmaniasis. - Indian. J. Med. Res. 123(3): 467.

6. Muniaraj, M., 2014. The lost hope of elimination of Kala-azar (visceral leishmaniasis) by 2010 and cyclic occurrence of its outbreak in India, blame falls on vector control practices or co-infection with human immunodeficiency virus or therapeutic modalities?. - Trop. Parasitol. 4(1): 10.

7. Joshi, G.C., Kaul, S.M. and Wattal, B.L., 1979. Susceptibility of sand flies to organochlorine insecticides in Bihar (India)-further reports. - J. Comm. Dis. 11(4): 209-213.

8. Mukhopadhyay, A.K., Chakravarty, A.K. and Kureel, V.R., 1987. Resurgence of Phlebotomus argentipes \& Ph. papatasi in parts of Bihar (India) after DDT spraying. -Indian. J. Med. Res. 85: 158-160.

9. Mukhopadhyay, A.K., Saxena, N.B., Narasimham, M.V.V. and World Health Organization, 1992. Susceptibility status of Phlebotomus argentipes to DDT in some kala-azar-endemic districts of Bihar, India. Geneva, World Health Organization, (document WHO/CTD/VBC/92.995). Indian. J. Med. Res. 91: 458-460.

10. Singh, R., Das, R.K. and Sharma, S.K., 2001. Resistance of sand flies to DDT in Kala-azar endemic districts of Bihar, India. - Bull. World. Health. Organ. 79: 793-793.

11. Dhiman, R.C., Raghavendra, K., Kumar, V., Kesari, S. and Kishore, K., 2003. Susceptibility status of Phlebotomus argentipes to insecticides in districts Vaishaii and Patna (Bihar). - J.Comm. Dis. 35(1): 49-51.

12. Kishore, K., Kumar, V., Kesari, S., Bhattacharya, S.K. and Das, P., 2004. Susceptibility of Phlebotomus argentipes against DDT in endemic districts of North Bihar, India. - J. Comm. Dis. 36(1): 41-44.

13. Singh, R. and Kumar, P., 2014. Susceptibility of the sand fly Phlebotomus argentipes Annandale and Brunneti (Diptera: Psychodidae) to insecticides in visceral leishmaniasis endemic areas of Bihar, India. - Jpn. J. Infect. Dis. 68(1): 33-37.

14. Coleman, M., Foster, G.M., Deb, R., Singh, R.P., Ismail, H.M., Shivam, P., Ghosh, A.K., Dunkley, S., Kumar, V., Coleman, M., Hemingway, J., Paine, M.J.I and Das, P., 2015. DDT- based indoor residual spraying suboptimal for visceral leishmaniasis elimination in India. - Proc. Natl. Acad. Sci. 112(28): 8573-8578.

15. Rama, A., Kumar, V., Kesari, S., Singh, V.P. and Das, P., 2015. Monitoring Susceptibility Status of Phlebotomus argentipes (Diptera: Psychodidae) at Bihar (India) for the Procurement of Homozygous DDT Resistant Colony. -J. Trop. Dis. 3(4): 170. doi:10.4172/2329891X.1000170.

16. Kumar, V., Shankar, L., Kesari, S., Bhunia, G.S., Dinesh, D.S., Mandal, R. and Das, P., 2015. Insecticide susceptibility of Phlebotomus argentipes $\&$ assessment of vector control in two districts of West Bengal, India. Indian. J. Med. Res. 142(2): 211.

17. Mulla, M.S., 1995. The future of insect growth regulators in vector control. - J. Am. Mosq. Control. Assoc. Mosq. News. 11(2): 269-273.

18. Tunaz, H. and Uygun, N., 2004. Insect growth regulators for insect pest control. - Turk. J. Agric. For. 28(6): 377-387.

19. Vasuki, V., 1992. Adult longevity of certain mosquito species after larval and pupal exposure to sublethal concentration of an insect growth regulator, hexaflumuron. -Southeast. Asian. J. Trop. Med. Public. Health. 23(1): 121-124.

20. Ritchie, S.A., Asnicar, M. and Kay, B.H., 1997. Acute and sublethal effects of (S)- methoprene on some Australian mosquitoes. - J. Am. Mosq. Control. Assoc. 13(2): 153-155.

21. Ali, A., Chowdhury, M.A., Hossain, M.I., Habiba, D.B. and Aslam, A.F., 1999. Laboratory evaluation of selected larvicides and insect growth regulators against field-collected Culex quinquefasciatus larvae from urban Dhaka, Bangladesh. -J. Am. Mosq. Control. Assoc. 15(1): 43-47.

22. Arredondo-Jimenez, J.I. and Valdez-Delgado, K.M., 2006. Effect of Novaluron (Rimon ${ }^{\circledR} 10 \mathrm{EC}$ ) on the mosquitoes Anopheles albimanus, Anopheles pseudopunctipennis, Aedes aegypti, Aedes albopictus and 
Rama et al. Trends in Vector Research and Parasitology 2021,

Culex quinquefasciatus from Chiapas, Mexico. -Med. Vet. Entomol. 20(4): 377-387.

23. Mascari, T.M., Mitchell, M.A., Rowton, E.D. and Foil, L.D., 2011. Evaluation of juvenile hormone analogues as rodent feed-through insecticides for control of immature phlebotomine sand flies. - Med. Vet. Entomol. 25(2): 227-231.

24. Mascari, T.M., Stout, R.W. and Foil, L.D., 2012. Evaluation of three feedthrough insecticides using two rodent and two sand fly species as models. - J. Am. Mosq. Control. Assoc. 28(3): 260-262.

25. Rama, A., Kesari, S., Das, P. and Kumar, V., 2017. Studying DDT susceptibility at discriminating time interval focusing maximum limit of exposure time survived by DDT resistant Phlebotomus argentipes (Diptera: Psychodidae)-an investigatory report. - Jpn. J. Infect. Dis. 70(4): 437-441.

26. Mascari, T.M., Mitchell, M.A., Rowton, E.D. and Foil, L.D., 2007. Evaluation of novaluron as a feed-through insecticide for control of immature sand flies (Diptera: Psychodidae). - J. Med. Entomol. 44(4): 714-717.

27. Mascari, T.M., Mitchell, M.A., Rowton, E.D. and Foil, L.D., 2007. Laboratory evaluation of diflubenzuron as a feed-through for control of immature sand flies (Diptera: Psychodidae). -J. Med. Entomol. 44(2): 171-174.

28. Rama, A., Kesari, S., Dinesh, D.S., Seema, K., Das, P. and Kumar, V., 2014. Vertebrate excreta based semiochemical influencing oviposition \& neonates' survival in Phlebotomus argentipes-Visceral leishmaniasis vector in Indian subcontinent. - J. Entomol. Zool. Stud. 2(6): 172-178.

29. Kumar, V., Rama, A., Kesari, S., Bhunia, G.S., Dinesh, D.S. and Das, P., 2013. Oviposition behaviour of Phlebotomus argentipes-A laboratorybased study. - Mem. Inst. Oswaldo. Cruz. 108(8): 1065-1067.

30. Kumar, V., Kesari, S., Dinesh, D.S., Tiwari, A.K., Kumar, A.J., Kumar, R., Singh, V.P. and Das, P., 2009. A report on the indoor residual spraying (IRS) in the control of Phlebotomus argentipes, the vector of visceral leishmaniasis in Bihar (India): an initiative towards total elimination targeting 2015 (Series-1). - J. Vector. Borne. Dis. 46(3): 225-229.

31. Kumar, V., Shankar, L., Rama, A., Kesari, S., Dinesh, D.S., Bhunia, G.S. and Das, P., 2015. Analysing host preference behavior of Phlebotomus argentipes (Diptera: Psychodidae) under the impact of indoor residual spray. - Int. J. Trop. Dis. Health. 7(2): 69-79.

32. Siddall, J.B., 1976. Insect growth regulators and insect control: a critical appraisal. - Environ. Health. Perspect. 14: 119.

33. Rama. A., Das. P. and Kumar, V. 2020. Exploring DDT modulated behavioral profile in terms of longevity, fecundity fertility and fitness (i.e., LF3) in subsequent generation of DDT resistant Phlebotomus argentipes (Diptera: Psychodidae). Curr. Sc. 119(1): 103-111.

34. Adler, S. and Theodor, O., 1957. Transmission of disease agents by phlebotomine s and flies. - Annu. Rev. Entomol. 2(1): 203-226.

35. Kalra, N.L. and Bang, Y.H., 1988. Manual on Entomology in Visceral Leishmaniasis. WHO, Regional Office for South-East Asia, New Delhi. $S E A / V B C / 35$.

\section{Citation:}

Rama A and Kumar V. Laboratory evaluation of Novalurone as an Insect Growth Regulator (IGR) against the immature DDT resistant Phlebotomus argentipes (Diptera: psychodidae). Trends Vector Res Parasitol. 2021; 8:2.

http://dx.doi.org/10.7243/2054-9881-8-2 